\title{
Variabilidade genética em cultivares de soja determinada com marcadores microssatélites em gel de agarose
}

\author{
Elisa Serra Negra Vieira(1), Ivan Schuster(1), Rosane Bezerra da Silva(2) e Marco Antônio Rott de Oliveira(1) \\ ${ }^{(1)}$ Cooperativa Central de Pesquisa Agrícola, BR 467, Km 98, CEP 83813-450 Cascavel, PR. E-mail: esnegra@coodetec.com.br, ivan@coodetec.com.br, \\ marco@coodetec.com.br (2)Universidade Paranaense, Rua Rui Barbosa, no 611, CEP 85810-240 Cascavel, PR. E mail: robsl.bio@gmail.com
}

Resumo - O objetivo deste trabalho foi avaliar a variabilidade genética de cultivares de soja com marcadores microssatélites selecionados e caracterizados quanto à informatividade para uso em gel de agarose. O DNA de 23 cultivares de soja foi amplificado com 283 marcadores microssatélites em gel de agarose a 3\%. Posteriormente, 53 marcadores que apresentaram polimorfismo facilmente detectável nos géis de agarose foram utilizados na caracterização de 53 cultivares. Nessas cultivares foram detectados 124 alelos, com média de 2,34 alelos por loco, e os valores de conteúdo de informação polimórfica variaram entre 0,16 e 0,66 , com média de 0,47 . As frequências alélicas variaram de 0,02 a 0,91 , com média de 0,43 . A distância genética calculada variou de 0,02 a 0,73 , com média de 0,47 . A menor distância observada foi entre as cultivares CD201 e CD208, e a maior distância entre CD210 e BRSMT Uirapuru. Os marcadores utilizados possibilitaram a identificação das 53 cultivares avaliadas. Os locos microssatélites de soja, avaliados em gel de agarose, apresentam elevada informatividade. É possível detectar variabilidade significativa no germoplasma brasileiro de soja avaliado, mesmo entre cultivares elite, quando se usa marcadores moleculares microssatélites selecionados por sua informatividade.

Termos para indexação: caracterização de cultivar, conteúdo de informação polimórfica, diversidade genética, frequência alélica, marcador SSR.

\section{Genetic variability of soybean cultivars obtained through microsatellite markers in agarose gel}

\begin{abstract}
The objective of this work was to evaluate the genetic variability of soybean cultivars with microsatellite markers selected and characterized for their informativity to be used in agarose gel system. The DNA of 23 soybean cultivars was amplified with 283 microsatellite markers, using a 3\% agarose gel systems. The 53 markers with clearly detectable polymorphism in the agarose gels were used to characterize 53 cultivars. In these 53 cultivars, 124 alleles were detected, with an average of 2.34 alleles per locus. Polymorphism information content values varied between 0.16 and 0.66 , with an average of 0.47 . Allele frequencies were of 0.02 to 0.91 , with an average of 0.43 . Genetic distance was of 0.02 to 0.73 , with an average value of 0.47 . The shortest distance was between cultivars CD201 and CD208, and the largest between CD210 and BRSMT Uirapuru. The markers used permitted the identification of all bean 53 cultivars. The soybean microssatellite loci evaluated in agarose gel presented high informativity. It is possible to detect significant variability in the Brazilian soybean germplasm evaluated, even among elite cultivars, when microssatellite molecular markers, selected for their informativity, are used.
\end{abstract}

Index terms: cultivar characterization, polymorphic information content, genetic diversity, allelic frequency, SSR marker.

\section{Introdução}

O conhecimento da diversidade genética e a relação entre cultivares melhoradas são de grande importância para o melhoramento das culturas. A diversidade genética assegura medidas de proteção contra problemas futuros como pragas ou doenças e fornece uma base para ganhos genéticos. A uniformidade genética, dentro de uma cultura, pode ser causada pelo uso extensivo de uma ou mais cultivares estreitamente relacionadas. A hibridização entre esse tipo de cultivares resulta em base genética estreita para as novas variedades (Bertini et al., 2006).
No Brasil, a soja [Glycine max (L.) Merrill] é responsável por um segmento econômico de alta expressão, que ocupa lugar de destaque na pauta de exportação do país. O Brasil é, atualmente, o segundo maior produtor mundial de soja. O bom desempenho da cultura deve-se principalmente à grande quantidade de cultivares melhoradas existentes e adaptadas a todas as regiões do país (Alcântara Neto, 2001).

Com a crescente demanda por cultivares adaptadas, produtivas e tolerantes a doenças, pragas e deficit hídrico, entre outras características, as empresas de pesquisa públicas e privadas têm buscado obter 
cultivares que atendam a essas necessidades. Assim, o número de cultivares das diversas espécies disponíveis nomercadotemaumentadosignificativamente(Schuster et al., 2006). Apesar do grande número de cultivares de soja existente no Brasil, há pouca variabilidade genética entre elas em razão, principalmente, de serem originárias de poucos ancestrais, o que resultou em uma base genética estreita (Alcântara Neto, 2001; Miranda et al., 2007).

Marcadores microssatélites têm provado ser uma excelente ferramenta para a avaliação da distância genética entre indivíduos, para a identificação de cultivares e para análises de pedigree (Priolli et al., 2002). Muitos trabalhos têm sido realizados com o uso de marcadores SSR na caracterização de cultivares de várias espécies de plantas como trigo, cevada e milho (Lima et al., 2003).

A soja é uma das culturas de interesse econômico que mais tem sido estudada por meio de marcadores moleculares, com as mais diversas finalidades, e com muitos trabalhos relacionados ao emprego de marcadores SSR na caracterização de suas cultivares (Narvel et al., 2000; Alcântara Neto, 2001, 2005; Bommi \& Ferguson, 2005).

Alguns relatos indicam que a diversidade genética das cultivares de soja no Brasil é estreita, seja com uso de dados morfológicos (Hiromoto \& Vello, 1986), ou de marcadores moleculares (Abdelnoor et al., 1995). No entanto, Bonato et al. (2006) apresentaram resultados de análises moleculares que demonstram que o germoplasma de soja, utilizado em programas de melhoramento no Brasil, manteve, em geral, nível constante de diversidade genética nos últimos anos, além de relativa heterogeneidade dentro de alguns desses programas.

Alguns autores recomendam a utilização de géis de agarose por questões de custo, facilidade de confecção e rapidez na visualização dos resultados, pois o tempo de corrida é mais rápido que nos géis de poliacrilamida. A utilização de géis de agarose é indicada porque muitos laboratórios apresentam apenas o equipamento para eletroforese nesses géis (Bommi \& Ferguson, 2005).

O objetivo deste trabalho foi avaliar a variabilidade genética de cultivares de soja, com um conjunto de marcadores microssatélites selecionados e caracterizados quanto à informatividade, para uso em gel de agarose.

\section{Materiais e Métodos}

As análises moleculares foram realizadas no Núcleo de Biotecnologia da Cooperativa Central de Pesquisa Agrícola (Coodetec), localizado em Cascavel, PR. Foram utilizadas 53 cultivares de soja, amplamente cultivadas e utilizadas nos programas de melhoramento no Brasil ( Tabela 1).

Uma amostra de sementes de cada cultivar foi moída e submetida à extração de DNA, conforme protocolo descrito por Schuster et al. (2004). Inicialmente, o DNA de 23 cultivares de soja da Coodetec foram amplificados com 283 marcadores microssatélites, selecionados de acordo com sua distribuição no mapa genético da soja (Song et al., 2004), para proporcionar ampla cobertura do genoma.

Tabela 1. Cultivares de soja utilizadas na caracterização molecular, instituição e natureza da instituição que forneceu o material.

\begin{tabular}{lcc}
\hline Cultivar & Instituição & Natureza da instituição \\
\hline CD 201, CD 202, CD 203, CD 204, CD 205, CD 206, CD 207, CD 208, & & Cooperativa \\
CD 209, CD 210, CD 211, CD 212RR, CD 213RR, CD 214RR, CD 215, & Coodetec & \\
CD 216, CD 217, CD 218, CD 219RR, CD 220, CD 221, CD 222, CD & \\
223AP, Ocepar 4. & & Pública \\
\hline BR 16, BRS 133, BRS 134, BES 154, BRS 184, BRS 232, Embrapa 48, & \\
Embrapa 59, BRS Sambaíba, BRSMG 68 Vencedora, BRSMG Liderança, & Embrapa & Pública \\
BRSMT Pintado, BRSMT Crixás, BRSMT Uirapuru, BRSGO Jataí, & Privada \\
MG/BR Conquista & & Privada \\
\hline Emgopa 315, Emgopa 316 & Emgopa \\
\hline FT Abyara, FT Cristalina & FT Sementes & Privada \\
\hline Msoy 6101, Msoy 8001, Msoy 8400, Msoy 8914, Msoy 9350 & Monsoy & Privada \\
\hline Spring, Vmax & Syngenta & - \\
\hline IAS 5 & Pioneer & Domínio público \\
\hline
\end{tabular}


As reações em cadeia de polimerase (PCR) foram realizadas em volume total de $20 \mu \mathrm{L}$, que continha: $30 \mathrm{ng}$ de DNA, 3 mmol L-1 de $\mathrm{MgCl}_{2}, 2 \mathrm{mmol} \mathrm{L}-1$ de Tris, 5 mmol L-1 de KCl, $250 \mu \mathrm{mol} \mathrm{L}^{-1}$ de dNTP, $0,4 \mu \mathrm{mol} \mathrm{\textrm {L } ^ { - 1 }}$ de cada iniciador (senso e anti-senso) e uma unidade de Taq DNA polimerase. As amplificações foram realizadas em termocicladores Thermo Hybaid (Ashford, Middlesex, Reino Unido) programado para um ciclo de $94^{\circ} \mathrm{C}$ por $3 \mathrm{~min}, 30$ ciclos de $94^{\circ} \mathrm{C}$ por $30 \mathrm{~s}, 50^{\circ} \mathrm{C}$ por $30 \mathrm{~s} \mathrm{e}, 72^{\circ} \mathrm{C}$ por $45 \mathrm{~s}$, e um ciclo final de $72^{\circ} \mathrm{C}$ por 10 min.

A separação dos fragmentos amplificados foi realizada em gel de agarose a $3 \%(0,7 \%$ de agarose e $1,15 \%$ de synergel) em cuba horizontal. O tampão utilizado, tanto para a confecção do gel quanto para o tanque, foi SB $0,5 \mathrm{X}\left(5 \mathrm{mmol} \mathrm{L}^{-1}\right.$ de hidróxido de sódio, ajustado para o $\mathrm{pH} 8$ com ácido bórico).

Os marcadores com perfis moleculares de fácil observação de polimorfismo em gel de agarose foram selecionados para teste em outras 30 cultivares de soja, representativas do germoplasma brasileiro.

A informatividade genética PIC (conteúdo de informação polimórfica), de cada loco microssatélite, foi avaliada por meio da frequência dos alelos, com a expressão: $\mathrm{PIC}=1-\sum_{\mathrm{j}=1}^{\mathrm{n}} \mathrm{p}_{\mathrm{ij}}^{2}$ em que $\mathrm{p}_{\mathrm{ij}}$ é a frequência do alelo $\mathrm{j}$ no marcador i.

As relações genéticas entre as cultivares foram avaliadas por meio de matriz de dissimilaridade, construída com uso do complemento do índice de similaridade para dados codominantes e multialélicos, com o auxílio do programa Genes (Cruz, 2001).
Esse índice foi obtido pela divisão do total de alelos comuns pelo número total de alelos avaliados em cada indivíduo.

A partir das estimativas de dissimilaridade, as cultivares foram agrupadas pelo método hierárquico UPGMA (unweighted pair-group mean average), com auxílio do programa Statistica (Statsoft, 1995).

\section{Resultados e Discussão}

Dos 283 marcadores avaliados, 123 foram monomórficos, 49 não amplificaram e 111 apresentaram polimorfismo entre as 23 cultivares de soja inicialmente avaliadas. Entre os marcadores polimórficos, alguns apresentaram maior separação dos alelos, mesmo em géis de agarose, enquanto outros apresentaram pequenas diferenças de tamanho entre os alelos, o que dificultou e tornou menos reprodutível a genotipagem das cultivares. A genotipagem das cultivares no loco Satt495 é menos confiável do que no loco Satt135 (Figura 1). Esperase esse tipo de resultado, quando as amplificações dos locos microssatélites são genotipadas em géis de agarose. Nesse sistema de genotipagem, alelos que apresentam diferenças menores do que dez pares de bases, no tamanho dos fragmentos, normalmente são difíceis de serem distiguidos. Por isso, é necessário selecionar o conjunto dos marcadores SSR que apresentarem diferenças maiores nos tamanhos dos fragmentos amplificados por cada alelo, para que esses iniciadores possam ser mais facilmente

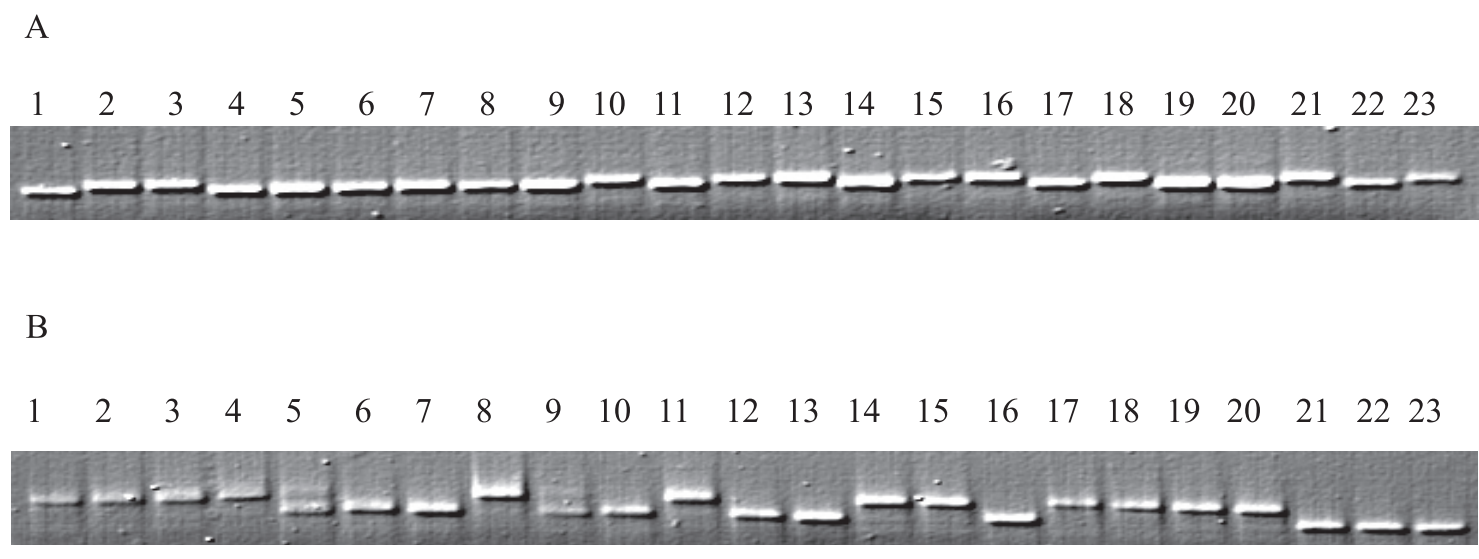

Figura 1. Padrões moleculares obtidos com os locos microssatélites Satt495 (A) e Satt135 (B), em 23 cultivares de soja. 
utilizados, quando a genotipagem for realizada em géis de agarose.

Os 111 pares de iniciadores polimórficos amplificaram 244 alelos nas 23 cultivares inicialmente avaliadas, com média de 2,20 por loco SSR. O valor do PIC calculado para estimar a informatividade de cada iniciador variou de 0,02 a 0,73 , com média de 0,40 . Narvel et al. (2000), ao estudar a diversidade genética entre variedades elite e acessos de germoplasma de soja, com 74 marcadores SSR, encontraram valores de PIC associados a cada marcador SSR que variaram de 0 a 0,79 com média de 0,50 nas variedades elite, e de 0 a 0,84 com média de 0,56 nos acessos utilizados.

Cinquenta e três marcadores apresentaram polimorfismo de fácil genotipagem em géis de agarose (Tabela 2). Com os dados das 53 cultivares avaliadas por meio dos 53 marcadores microssatélites, foram obtidos 124 alelos, com média de 2,34 por loco. O valor de PIC variou entre 0,16 e 0,66 , com média de 0,47 .

Segundo Schuster et al. (2006), se as frequências alélicas são conhecidas, é possível estimar as probabilidades de identidade de uma determinada cultivar com qualquer outra, com base na análise de DNA. Na Tabela 2, estão apresentadas as frequências de todos os alelos observados. Na genotipagem a partir de géis de agarose, a estimativa dos tamanhos dos alelos não é precisa, e as comparações sempre devem ser realizadas com amostras representativas de cada alelo no mesmo gel. Por este motivo, na Tabela 2 está indicada uma cultivar representativa de cada alelo, para que os dados de frequência alélica possam ser utilizados para identificar a correspondência com os alelos deste trabalho; para isto, basta utilizar a cultivar representativa de cada alelo e genotipar as amostras de acordo com o alelo que apresentam.

A dissimilaridade genética, calculada entre as 53 cultivares, variou de 0,02 a 0,73 , com média de 0,47 . A menor distância observada ocorreu entre as cultivares CD201 e CD208, enquanto a maior distância foi entre CD210 e BRSMT Uirapuru. As 53 cultivares foram separadas em sete grupos de acordo com a distância genética entre elas (Figura 2). Brown-Guerida et al. (2000) obtiveram resultado semelhante com 105 acessos de soja. A distância encontrada por esses autores variou de 0,08 a 0,76 , com média de 0,52 , formando 11 grupos distintos.
O conjunto de 53 locos SSR utilizados distinguiu completamente todas as cultivares avaliadas. Foi possível distinguir, inclusive, as cultivares CD201 e CD208, que apresentam coeficiente de parentesco de $99,22 \%$ pela genealogia.

$\mathrm{Na}$ Figura 2, pode-se observar que as cultivares com sigla CD (Coodetec) formaram grupos exclusivos, enquanto as de outros programas de melhoramento estão distribuídas nos demais grupos. Das 23 cultivares Coodetec avaliadas, apenas duas - CD210 e CD 216 estão fora destes grupos.

Embora muitos trabalhos tenham demonstrado que a soja possui estreita variabilidade genética, tanto nos EUA (Gizlice et al., 1994) quanto no Brasil (Hiromoto \& Vello, 1986; Abdelnoor et al., 1995), a utilização de marcadores moleculares microssatélites, selecionados por sua informatividade, permitiu detectar uma quantidade significativa de variabilidade. Foi observada variabilidade mesmo entre cultivares elite, das quais esperava-se obter menor variabilidade, uma vez que o melhoramento genético leva, potencialmente, a um estreitamento da variabilidade genética (Miranda et al., 2007).

Embora os marcadores moleculares utilizados no presente trabalho não tenham associação com características relacionadas à produtividade das cultivares, eles constituem uma amostra representativa do genoma da soja (Tabela 2). Assim, se as cultivares apresentam variabilidade bem distribuída nessa regiões do genoma, é, também, provável que apresentem variabilidade em genes expressos, muitos dos quais podem estar associados à produtividade. Os resultados obtidos podem indicar que há, ainda, bastante variabilidade genética no germoplasma brasileiro de soja a ser explorada pelos programas de melhoramento.

Com a utilização de géis de agarose, foi possível detectar a variabilidade genética existente entre cultivares elite de soja. Para tanto, foram selecionados marcadores específicos para a utilização neste sistema de detecção, o que reduziu a amostragem do genoma.

Os marcadores selecionados para a utilização em géis de agarose, neste trabalho, podem ser utilizados para detectar a variabilidade e a identidade genética das cultivares de soja. As informações de frequências alélicas, em cada loco, permitem calcular a probabilidade de identidade ao acaso e a probabilidade de exclusão de identidade ao acaso, o que indica se duas

Pesq. agropec. bras., Brasília, v.44, n.11, p.1460-1466, nov. 2009 
amostras possuem ou não o mesmo genótipo (Schuster et al., 2006). Esta informação pode ser utilizada para distinguir genótipos considerados iguais com base nos descritores morfológicos em processos de registro e proteção de cultivares. Pode ser utilizada também para comprovar a identidade genética de uma cultivar,

Tabela 2. Iniciadores polimórficos utilizados na avaliação de 53 cultivares de soja, localização no genoma da soja (LG), número de alelos observados, cultivar representativa dos alelos, frequências alélicas e valores de conteúdo de informação polimórfica (CIP).

\begin{tabular}{|c|c|c|c|c|c|}
\hline Iniciadores $^{(1)}$ & LG & $\mathrm{N}^{\mathrm{o}}$ de Alelos & Alelos da cultivar exemplo ${ }^{(2)}$ & Frequências alélicas & CIP \\
\hline Sat_001 & D2 & 3 & a: BRS154; b: CD206; c: BRS232 & a: 0,$49 ; b: 0,36 ; c: 0,15$ & 0,61 \\
\hline Sat_099 & $\mathrm{L}$ & 2 & a: BRSMG Liderança; b: CD204 & a: 0,$91 ; b: 0,09$ & 0,16 \\
\hline Sat_105 & I & 3 & a: BRS134; b: CD216; c: Msoy 8001 & a: 0,$23 ; b: 0,42 ; c: 0,34$ & 0,66 \\
\hline Sat_115 & $\mathrm{A} 2$ & 3 & a: BRS184; b: CD218; c: BRS133 & a: 0,$46 ; b: 0,44 ; c: 0,10$ & 0,58 \\
\hline Sat_168 & G & 3 & $\begin{array}{l}\text { a: MG/BR Conquista; b: CD213RR; } \\
\text { c: FT Abyara }\end{array}$ & $\begin{array}{l}\text { a: } 0,09 ; \text { b: } 0,22 \\
\text { c: } 0,69\end{array}$ & 0,47 \\
\hline Satt020 & $\mathrm{B} 2$ & 2 & a: Embrapa 59; b: CD207 & a: 0,$32 ; b: 0,68$ & 0,44 \\
\hline Satt094 & $\mathrm{O}$ & 2 & a: BRSMG 68 Vencedora; b: CD215 & a: 0,$62 ; b: 0,38$ & 0,47 \\
\hline Satt194 & $\mathrm{C} 1$ & 2 & a: BRS Sambaíba; b: CD214RR & $\mathrm{a}: 0,50 ; \mathrm{b}: 0,44$ & 0,56 \\
\hline Satt181 & $\mathrm{H}$ & 3 & a: CD210; b; CD211; c: Embrapa 48 & a: 0,$36 ; b: 0,31 ; c: 0,34$ & 0,67 \\
\hline Satt200 & A1 & 2 & a: BRSMT Uirapuru; b: CD210 & $\mathrm{a}: 0,49 ; \mathrm{b}: 0,51$ & 0,5 \\
\hline Satt216 & D1b & 4 & $\begin{array}{l}\text { a: BRSMT Pintado; b: CD208; } \\
\text { c: BRSMT Crixás; d: BRS } 68 \text { Vencedora }\end{array}$ & $\begin{array}{l}\text { a: } 0,29 ; \text { b: } 0,48 \\
\text { c: } 0,04 ; \text { d: } 0,19\end{array}$ & 0,65 \\
\hline Satt253 & $\mathrm{H}$ & 2 & $\mathrm{a}:$ CD207; b: IAS 5 & a: 0,$57 ; b: 0,43$ & 0,49 \\
\hline Satt285 & $\mathrm{J}$ & 2 & a: FT Abyara; b: FT Cristalina & a: 0,$44 ; b: 0,56$ & 0,49 \\
\hline Satt301 & D2 & 2 & a: BRS134; b: CD205 & a: 0,$12 ; b: 0,51$ & 0,59 \\
\hline Satt302 & $\mathrm{H}$ & 2 & a: Emgopa 315 ; b: Conquista & a: 0,$47 ; b: 0,53$ & 0,47 \\
\hline Satt307 & $\mathrm{C} 2$ & 3 & a: CD209; b: Msoy 9350; c: Msoy 8914 & a: 0,$32 ; b: 0,38 \mathrm{c}: 0,29$ & 0,66 \\
\hline Satt371 & $\mathrm{C} 2$ & 2 & a: CD211; b: Emgopa 316 & a: 0,$65 ; b: 0,33$ & 0,47 \\
\hline Satt386 & D2 & 2 & a: CD205; b: CD204 & $\mathrm{a}: 0,83 ; \mathrm{b}: 0,17$ & 0,28 \\
\hline Satt426 & B1 & 2 & a: BRS Sambaíba; b:Vmax & a: 0,$15 ; b: 0,85$ & 0,25 \\
\hline Satt464 & D2 & 2 & a: CD203; b: BRSMT Crixás & a: 0,$71 ; b: 0,29$ & 0,41 \\
\hline Sat_141 & $\mathrm{G}$ & 2 & a: BRS154; b: BRS232 & $\mathrm{a}: 0,20 ; \mathrm{b}: 0,80$ & 0,32 \\
\hline Sat_294 & A2 & 2 & a: BRS134; b: 154 & a: 0,$22 ; b: 0,78$ & 0,34 \\
\hline Satt173 & $\mathrm{O}$ & 2 & a: BRSMT Uirapuru; b: CD223 & $\mathrm{a}: 0,55 ; \mathrm{b}: 0,39$ & 0,54 \\
\hline Satt175 & M & 3 & a: CD221; b: Ocepar 4; c: BRS232 & a: 0,$27 ; b: 0,69 ; c: 0,04$ & 0,45 \\
\hline Satt191 & G & 3 & a: BR16; b: BRS134; c: CD217 & a: 0,$37 ;$ b: 0,$57 ;$ c: 0,04 & 0,54 \\
\hline Satt303 & G & 3 & a: C206; b: BRS133; c: BRS184 & a: 0,$21 ; b: 0,67 ; c: 0,08$ & 0,50 \\
\hline Satt335 & $\mathrm{F}$ & 3 & a: BRS Sambaíba; b: BRS 68 Vencedora & $\mathrm{a}: 0,53 ; \mathrm{b}: 0,47$ & 0,50 \\
\hline Satt352 & $\mathrm{G}$ & 2 & $\mathrm{a}: \mathrm{CD} 218 ; \mathrm{b}: \mathrm{CD} 217$ & $\mathrm{a}: 0,74 ; \mathrm{b}: 0,26$ & 0,39 \\
\hline Satt417 & $\mathrm{K}$ & 2 & a: BR16; b: CD217 & $\mathrm{a}: 0,63 ; \mathrm{b}: 0,37$ & 0,47 \\
\hline Satt449 & A1 & 3 & a: CD222; b: BRS Sambaíba; c: BRSMT Pintado & a: 0,$18 ; b: 0,39 ;$ c: 0,43 & 0,68 \\
\hline Satt485 & $\mathrm{N}$ & 2 & a: Embrapa 59; b: CD212RR & a: 0,$63 ; b: 0,37$ & 0,46 \\
\hline Satt540 & M & 2 & a: BRS134; B: CD212RR & $\mathrm{a}: 0,53 ; \mathrm{b}: 0,47$ & 0,50 \\
\hline Satt545 & A1 & 2 & a: CD202; b: BR16 & a: 0,$64 ; b: 036$ & 0,46 \\
\hline Satt564 & G & 2 & a: CD203; b: BRSMT Uirapuru & $\mathrm{a}: 0,60 ; \mathrm{b}: 0,40$ & 0,48 \\
\hline Satt579 & D1b & 2 & a: CD218; b: Msoy 8400 & $\mathrm{a}: 0,58 ; \mathrm{b} ; 0,42$ & 0,49 \\
\hline Satt596 & $\mathrm{J}$ & 2 & a: CD223; b:Msoy 6101 & $\mathrm{a}: 0,85 ; b ; 0,15$ & 0,26 \\
\hline Satt423 & $\mathrm{F}$ & 2 & a: CD209; b; BRSMT Pintado & $\mathrm{a}: 0,59 ; \mathrm{b}: 0,41$ & 0,49 \\
\hline Satt233 & $\mathrm{A} 2$ & 3 & a: CD210; b; CD214RR; c: Emgopa 315 & a: 0,$13 ; b: 0,43 ; c: 0,43$ & 0,61 \\
\hline Satt600 & D1b & 2 & a: CD202; b: Embrapa 59 & a: 0,$72 ; b: 0,28$ & 0,41 \\
\hline Satt663 & $\mathrm{F}$ & 2 & a: CD214RR; b: FT Abyara & $\mathrm{a}: 0,86 ; \mathrm{b}: 0,14$ & 0,24 \\
\hline Satt685 & $\mathrm{E}$ & 2 & a: DM Nobre; b: BRSGO Jataí & $\mathrm{a}: 0,73 ; \mathrm{b}: 0,27$ & 0,40 \\
\hline Satt703 & D1b & 2 & a: CD220; b: Msoy 8001 & $\mathrm{a}: 0,53 ; \mathrm{b}: 0,45$ & 0,52 \\
\hline Satt728 & M & 2 & a: Msoy 6101; b: CD205 & $\mathrm{a}: 0,54 ; \mathrm{b}: 0,42$ & 0,53 \\
\hline Satt070 & $\mathrm{B} 2$ & 3 & $\begin{array}{l}\text { a: Pintado; b: BRSMG Liderança; } \\
\text { c: BRSMG } 68 \text { Vencedora }\end{array}$ & a: 0,$24 ; b: 0,31 ; c: 0,45$ & 0,64 \\
\hline Satt136 & $\mathrm{C} 1$ & 2 & a: BRS 133; b: BR 16 & $\mathrm{a}: 0,13 ; \mathrm{b}: 0,87$ & 0,23 \\
\hline Satt311 & D2 & 3 & a: CD 202; b: BRS 133; c: CD 216 & a: 0,$27 ; b: 0,46 ; c: 0,27$ & 0,64 \\
\hline Satt358 & $\mathrm{O}$ & 2 & a: CD 202; b: BRS 133 & a: 0,$37 ; b: 0,63$ & 0,47 \\
\hline Satt431 & $\mathrm{J}$ & 2 & a: BRS 133; b: CD202 & $\mathrm{a}: 0,55 ; \mathrm{b}: 0,45$ & 0,50 \\
\hline Satt406 & $\mathrm{J}$ & 3 & a: FT Abyara; b: BRS 133; c: CD 215 & a: 0,$06 ; b: 0,27 ; c: 0,67$ & 0,50 \\
\hline Satt135 & D2 & 2 & $\mathrm{a}:$ CD 202; b: BRS 133 & $\mathrm{a}: 0,58 ; \mathrm{b}: 0,42$ & 0,49 \\
\hline Satt184 & D1a & 3 & a: CD 202; b: CD203; c: BRS 133 & a: 0,$23 ; b: 0,02 ; c: 0,75$ & 0,39 \\
\hline Satt197 & B1 & 2 & a: CD 202; b: CD216 & a: 0,$91 ; b: 0,09$ & 0,17 \\
\hline Sat_085 & $\mathrm{C} 1$ & 2 & a: CD 202; b: BRS 133 & a: 0,$47 ; b: 0,53$ & 0,50 \\
\hline Total & & 124 & & & \\
\hline Média & & 2,34 & & & 0,47 \\
\hline
\end{tabular}

${ }^{(1)}$ A sequência dos iniciadores pode ser obtida em http://soybase.org/resources/ssr.php. (2)Para cada alelo, é apresentada uma cultivar exemplo que o possui. 
em casos de proteção da propriedade intelectual. No entanto, para utilizar dados obtidos a partir de géis de agarose, em processos de identificação genética de cultivares, é necessário que a análise seja comparativa, com as amostras a serem distinguidas no mesmo gel. As cultivares indicadas como referência de cada

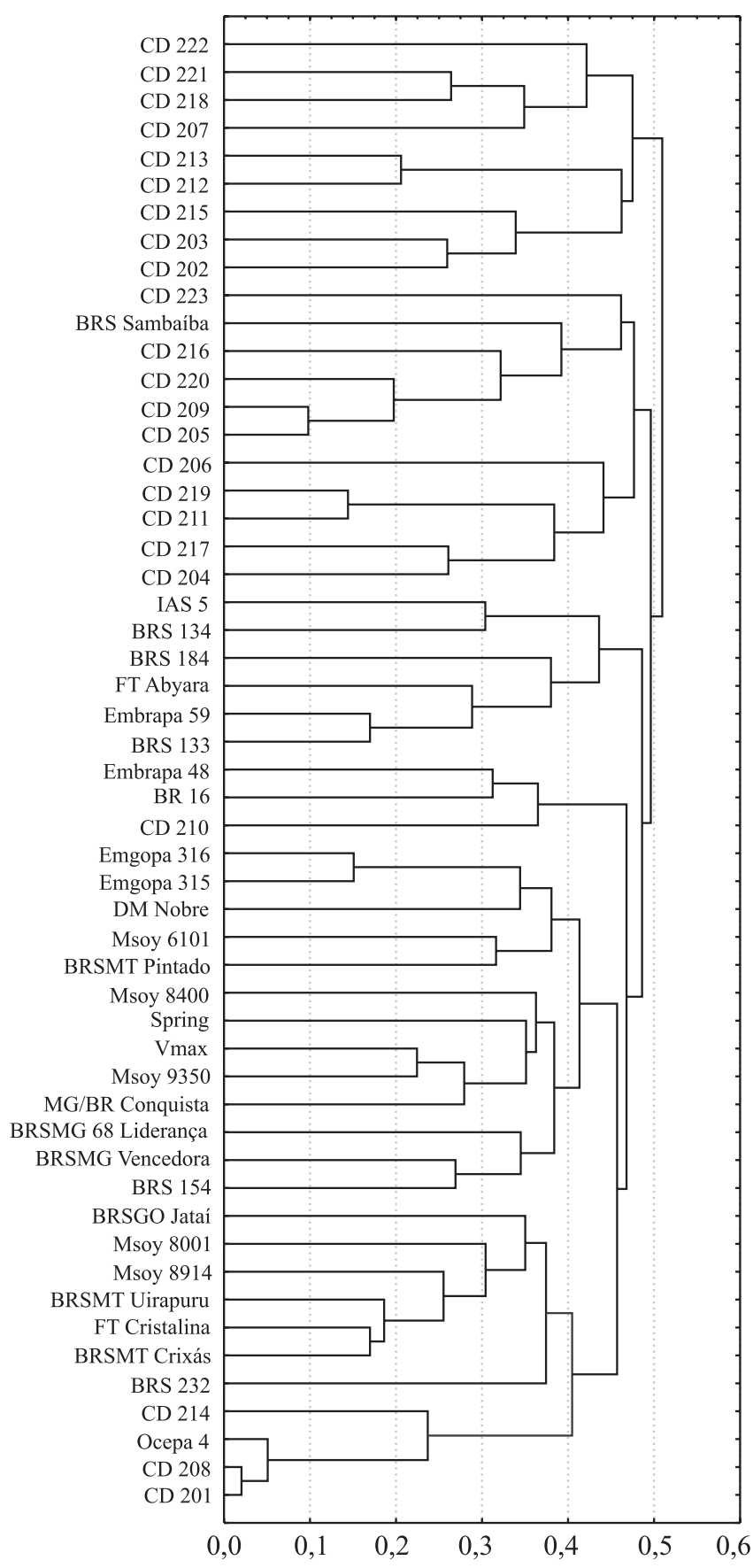

Figura 2. Agrupamento de 53 cultivares de soja, pelo método UPGMA, em função das dissimilaridades genéticas obtidas por marcadores moleculares microssatélites. alelo, nos 53 locos identificados, podem ser utilizadas como guias para a identificação dos alelos, para que as frequências alélicas sejam usadas na estimativa das probabilidades de identidade genética.

De 111 marcadores identificados como polimórficos, 53 puderam ser observados em agarose (Tabela 2), pois as diferenças entre os tamanhos dos alelos observados nas cultivares representativas do germoplasma brasileiro de soja possiblitaram a genotipagem. Os outros 58 marcadores também são informativos, mas é necessário que a separação dos fragmentos seja realizada em géis de maior resolução, como por exemplo, géis desnaturantes de poliacrilamida, ou em analisadores genéticos automáticos, utilizados para sequenciamento de DNA.

\section{Conclusões}

1. Os 53 locos microssatélites de soja, avaliados em gel de agarose, apresentam elevada informatividade.

2. É possível detectar significativa variabilidade no germoplasma brasileiro de soja avaliado, mesmo entre cultivares elite, quando se usam marcadores moleculares microssatélites selecionados por sua informatividade.

\section{Agradecimentos}

À Cooperativa Central de Pesquisa Agrícola e à Universidade Paranaense, pelo apoio financeiro para a realização deste trabalho.

\section{Referências}

ABDELNOOR, R.V.; BARROS, E.G. de; MOREIRA, M.A. Determination of genetic diversity within Brazilian soybean germplasm using random amplified polymorphic DNA techniques and comparative analysis with pedigree data. Revista Brasileira de Genética, v.18, p.265-273, 1995.

ALCÂNTARA NETO, F. Caracterização genético-molecular de um banco ativo de germoplasma de soja. 2005. 75p. Tese (Doutorado) - Universidade Federal de Viçosa, Viçosa.

ALCÂNTARA NETO, F. Marcadores microssatélites na identificação de cultivares de soja. 2001. 46p. Tese (Mestrado) Universidade Federal de Viçosa, Viçosa.

BERTINI, C.H.C. de M.; SCHUSTER, I.; SEDIYAMA, T.; BARROS. E.G. de; MOREIRA, M.A. Characterization and genetic diversity analysis of cotton cultivars using microsatellites. Genetics and Molecular Biology, v.29, p.321-329, 2006.

BOMMI, P.; FERGUSON, D.L. Soybean cultivar identification within a selected group using only an agarose gel system with 
simple sequence repeat DNA markers. Soybean Genetics Newsletter, v.32, p.1-7, 2005.

BONATO, A.L.V.; CALVO, E.S.; GERALDI, I.O.; ARIAS, C.A.A. Genetic similarity among soybean (Glycine $\max (\mathrm{L}$.$) Merrill)$ cultivars released in Brazil using AFLP markers. Genetics and Molecular Biology, v.29, p.692-704, 2006.

BROWN-GUERIDA, G.L.; THOMPSON, J.A.; NELSON, R.L.; WARBURTON, M.L. Evaluation of genetic diversity of soybean introductions and North American ancestors using RAPD and SSR markers. Crop Science, v.40, p.815-823, 2000.

CRUZ, C.D. Programa GENES: aplicativo computacional em genética e estatística. Versão Windows. Viçosa: UFG, 2001. 648p.

GIZLICE, Z.; CARTER, T.E.; BURTON, J.W. Genetic base for North American public soybean cultivars released between 1947 and 1988. Crop Science, v.34, p.1143-1151, 1994.

HIROMOTO, D.M.; VELLO, N.A. The genetic base of Brazilian soybean (Glycine $\max$ (L.) Merrill) cultivars. Revista Brasileira de Genética, v.9, p.295-306, 1986.

LIMA, V.L. de A.; SEKI, H.A.; RUMJANEK, F.D. Microsatellite polymorphism in wheat from Brazilian cultivars; inter- and intravarietal studies. Genetics and Molecular Biology, v.26, p.349$353,2003$.

MIRANDA, Z.F.S.; ARIAS, C.A.A.; PRETE, C.E.C.; KIHL, R.A. de S.; ALMEIDA, L.A. de A.; TOLEDO, J.F.F. de; DESTRO, D. Genetic characterization of ninety elite soybean cultivars using coefficient of parentage. Pesquisa Agropecuária Brasileira, v.42, p.363-396, 2007.

NARVEL, J.M.; FERHR, W.R.; CHU, W-C.; GRANT, D.; SHOEMAKER, R.C. Simple sequence repeat diversity among soybean plant introductions and elite genotypes. Crop Science, V.40, p.1452-1458, 2000.

PRIOLLI, R.H.G.; MENDES-JUNIOR, C.T.; ARANTES, C.E.; CONTEL, E.P.B.. Characterization of Brazilian soybean cultivars using microsatellite markers. Genetics and Molecular Biology, v.25, p.185-193, 2002.

SCHUSTER, I.; QUEIROZ, V.T. de; TEIXEIRA, A.I.; BARROS, E.G. de; MOREIRA, M.A. Determinação da pureza varietal de sementes de soja com auxílio de marcadores moleculares microssatélites. Pesquisa Agropecuária Brasileira, v.39, p.247253, 2004.

SCHUSTER, I.; VIEIRA, E.S.N.; PADILHA, L. Marcadores moleculares no pós-melhoramento. In: BORÉM, A.; CAIXETA, E.T. (Ed.). Marcadores moleculares. Viçosa: UFV, 2006. p.205220.

SONG, Q.J.; MAREK, L.F.; SHOEMAKER, R.C.; LARK, K.G.; CONCIBIDO, V.C.; DELANNAY, X.; SPECHT, J.E.; CREGAN, P.B. A new integrated genetic linkage map of the soybean. Theoretical and Applied Genetics, v.109, p.122-128, 2004.

STATSOFT. STATISTICA for Windows (Computer program manual). Tulsa: StatSoft, 1995.

Recebido em 27 de julho de 2009 e aprovado em 20 de outubro de 2009 